\title{
COMPARISON ANALYSIS OF NEWBORN BIRTHING WITH VAGINAL DELIVERY AND CESAREAN SECTION
}

\author{
Magdalena Roguska', Łukasz Czyżewski², Janusz Wyzgał², \\ Izabela Sztybor ${ }^{3}$, Dominika Dunder ${ }^{3}$, Emilia Czyżewska ${ }^{4}$ \\ ${ }^{1}$ Student of Faculty of Health Sciences, Collegium Mazovia Innovative University, Siedlce, Poland \\ ${ }^{2}$ Department of Nephrology Nursing, Medical University of Warsaw, Poland \\ ${ }^{3}$ Lazarski University, Warsaw, Poland \\ ${ }^{4}$ Department of Laboratory Diagnostics, Medical University of Warsaw, Warsaw, Poland
}

\begin{abstract}
INTRODUCTION: Most of them perceive a vaginal delivery as morbid, painful, often complicated. Fear of pain, fear of a child, negative experiences associated with a previous birth and the opinions of relatives often contribute to the termination of pregnancy through cesarean section without medical indications "cesarean section on demand". The aim of the study was to compare the state of newborns born with vaginal delivery with newborns born through caesarean section.
\end{abstract}

METHODS: The research was carried out in January 2018 at the District Hospital in Węgrów (Poland) at the Neonatology Department. 47 consecutive newborns of the Neonatological Department born in January 2018, were included in the study.

RESULTS: The study group consisted of 47 newborns - 27 (57\%) newborns were enrolled in the group of neonates born via caesarean section. The termination of pregnancy occurred usually at week $39( \pm 1)$, and the average age of the maternal mothers is 30 years $( \pm 5)$. The child's weight is $3622 \mathrm{~g}( \pm 523)$, umbilical cord pH 7.359 ( \pm 0.052 ). Maternal age does not seem to have a significant impact on the type of delivery in the case of caesarean section, the average age is 29 years $( \pm 6)$, in terms of childbirth, the mother's age is 30 years $( \pm 6)$.

CONCLUSIONS: In conclusion, our data indicate that: (1) The average weight of neonates born via caesarean section is higher than the postnatal weight of newborns from vaginal delivery; (2) There is a relationship between the mother's age and the $\mathrm{pH}$ value of umbilical cord blood and postnatal weight of the child; (3) Transient and vomiting are more common in neonates born by caesarean section in the adaptive period; (4) The type of delivery does not affect the $\mathrm{pH}$ of umbilical cord blood of a newborn.

KEY WORDS: caesarean section, vaginal delivery, neonatal outcome

Disaster Emerg Med J 2018; 3(3): 91-95

\section{INTRODUCTION}

In the last dozen or so years a significant increase in the number of cesarean sections can be observed. According to the recommendations of the World
Health Organization (WHO), only $10-15 \%$ of deliveries should end in operation. In Poland, meanwhile, the number of imperial cuts performed exceeds $30 \%$ of all births. 
According to the position of the Polish Gynecological Society (PGS), the caesarean section is aimed at completing pregnancy or childbirth when further waiting for their natural ending is a danger to the mother or child. The most common indications for the operational completion of pregnancy are: threatening intrauterine fetal distress, abnormal positioning, lack of delivery progress and condition after cesarean section. In addition to medical indications, the factors that contribute to the increase in the operating percentage of pregnancy completion are more and more often is the will of mothers, as well as concerns of obstetricians about possible claims as a consequence of complications during vaginal delivery. In many cases, the future mother's psychological approach to the delivery by vaginal route has a huge impact on the decision about the method of pregnancy.

Most of them perceive a vaginal delivery as morbid, painful, often complicated. Fear of pain, fear of a child, negative experiences associated with a previous birth and the opinions of relatives often contribute to the termination of pregnancy through cesarean section without medical indications "cesarean section on demand". Women are forgetting that the cesarean section, despite significant progress in medicine, is an operation that carries the risk of intra and postoperative complications. The widespread opinion that it is burdened with a lower risk of threats compared to vaginal delivery is therefore not entirely compatible with the actual state of affairs.

An elective caesarean section reduces the risk of intrauterine hypoxia, perinatal injuries and tar suspension syndrome. Nevertheless, it is not a natural way of delivery and carries the risk of adaptation problems in ectopic conditions. Cesarean section causes respiratory failure in the course of transient acceleration syndrome, respiratory distress syndrome and pulmonary hypertension syndrome both in newborns as well as in "late preterm infants". Therefore, children delivered by cesarean sections compared to vaginal delivery ones in many cases require extended stay in the hospital, as well as the use of advanced medical procedures such as mechanical ventilation [1, 2].

Childbirth is the stage of developing the relationship between mother and child. It is formed on the basis of satisfying the basic needs of the child such as: sucking, ensuring the right temperature and protection against the stimuli of the outside world. The situation that allows the mother to interact with the child is contact "skin to the skin" immediately after giving birth. Such contact lasting at least two hours is recommended for all healthy newborns regardless of the delivery route, This contact is disturbed after cesarean section which has an adverse effect on the psychological, medical and health aspects of the newborn $[3,4]$.

Caesarean section is a procedure that arouses much controversy. It has already been used in antiquity, it was initially used as a fetal life-saving surgery, now it is very often performed without specific indications. Perceived by society as a simple and most comfortable way to give birth to children.

The aim of the study was to compare the state of newborns delivered by vaginal route with newborns delivered through caesarean section.

\section{METHODS}

The research was carried out in January 2018 at the District Hospital in Węgrów (Poland) at the Neonatology Department. 47 consecutive newborns of the Neonatological Department born in January 2018 were included in the study. The research was carried out in accordance with the principles of ethics - The Declaration of Helsinki.

The study excluded newborns who: (1) died immediately after delivery; (2) there was a need to transport a higher reference level to the institution immediately after delivery.

Newborns were divided into two groups: newborns born by vaginal delivery and newborns born via caesarean section for comparative analysis. In addition, a division was made based on the sex of the newborn, the age of the mother and the weight after the birth of the newborn.

\section{STATISTICAL ANALYSIS}

Results concerning quantitative variables were presented as average values \pm standard deviation. Qualitative variables (age, sex) were presented as quantity (n) and percentage values of the whole group (\%) while proportions in groups were assessed with a T-student test. Statistica 13.1 software (StatSoft Inc., Tulsa, OK) was used in the statistical analysis. $\mathrm{P}<0.05$ was adopted as the significance level.

\section{RESULTS}

The study group consisted of 47 newborns - 27 (57\%) newborns were enrolled in the group 
of neonates born via caesarean section. Table 1 presents the general characteristics of the group of newborns examined, which shows that the number of pregnancies and deliveries is on average $2( \pm 1)$. The termination of pregnancy occurred usually at week $39( \pm 1)$, and the average age of the maternal mothers is 30 years of age $( \pm 5)$. The child's weight is $3622 \mathrm{~g}( \pm 523)$, umbilical cord pH 7.359 ( \pm 0.052$)$.

Table 2 shows the division of newborns due to the type of delivery. There were no statistically significant differences between the type of delivery and the number of pregnancies, which are on average $2( \pm 1)$. Maternal age does not seem to have a significant impact on the type of delivery in the case of caesarean section, the average age is 29 years of age $( \pm 6)$, in terms of childbirth, the mother's age is

Table 1. General characteristics of the group of
newborns examined
\begin{tabular}{|l|l|}
\hline Number of pregnancies & $2 \pm 1$ \\
\hline Age of the maternal mothers [y] & $30 \pm 5$ \\
\hline Termination of pregnancy [week] & $39 \pm 1$ \\
\hline Apgar scale [pts] & $10 \pm 1$ \\
\hline Child's weight [g] & $3622 \pm 523$ \\
\hline Umbilical cord pH & $7,359 \pm 0,052$ \\
\hline Glucose [mg\%] & $74 \pm 16$ \\
\hline Bilirubin [mg/dl] & $1,4 \pm 2,5$ \\
\hline Saturation [\%] & $98 \pm 1$ \\
\hline Heart rate [bpm] & $124 \pm 10$ \\
\hline
\end{tabular}

\begin{tabular}{|c|c|c|c|}
\hline & $\begin{array}{c}\text { Caesarean } \\
\text { section }\end{array}$ & $\begin{array}{l}\text { Vaginal } \\
\text { delivery }\end{array}$ & $P$ \\
\hline $\begin{array}{l}\text { Number of } \\
\text { pregnancies }\end{array}$ & $2 \pm 1$ & $2 \pm 1$ & 0,700 \\
\hline Mother's age [y] & $29 \pm 6$ & $30 \pm 6$ & 0,153 \\
\hline $\begin{array}{l}\text { Pregnancy } \\
\text { termination [week] }\end{array}$ & $39 \pm 1$ & $39 \pm 1$ & 0,448 \\
\hline Apgar scale [pts] & $9 \pm 0,7$ & $10 \pm 0,0$ & 0,048 \\
\hline $\begin{array}{l}\text { Weight of } \\
\text { newborns [g] }\end{array}$ & $3729 \pm 520$ & $3477 \pm 505$ & 0,102 \\
\hline $\begin{array}{l}\text { Umbilical cord } \\
\text { blood pH }\end{array}$ & $\begin{array}{l}7,367 \pm \\
0,039\end{array}$ & $\begin{array}{l}7,348 \pm \\
0,065\end{array}$ & 0,220 \\
\hline Glucose [mg\%] & $79 \pm 18$ & $82 \pm 20$ & 0,414 \\
\hline Bilirubin [mg/dl] & $1,5 \pm 2,6$ & $1,9 \pm 2,9$ & 0,982 \\
\hline Saturation [\%] & $98 \pm 1$ & $97 \pm 1$ & 0,011 \\
\hline Heart rate $[\mathrm{bpm}]$ & $122 \pm 9$ & $123 \pm 8$ & 0,125 \\
\hline
\end{tabular}

30 years of age $( \pm 6)$. The pregnancy termination in both cases occurs in 39 weeks $( \pm 1)$. Natural delivery scoring according to the Apgar scale is 10pts ( \pm $0)$, similarly caesarean section maintains the value of 10 points $( \pm 1)$. The visible differences can be seen in the weight of newborns born with caesarean section $3729 \mathrm{~g}( \pm 520)$, which is significantly higher than the weight of newborns born via the vaginal route $3477 \mathrm{~g}( \pm 505)$. The umbilical cord blood $\mathrm{pH}$ at caesarean section is $7.367( \pm 0.039)$, slightly different from the second type of delivery where it is $7.348( \pm 0.065)$. The value of glucose from umbilical cord blood after C/S (Ceasarian Section) is $79 \mathrm{mg} \%( \pm 18)$ and $82 \mathrm{mg} \%( \pm 20)$ after natural birth. The bilirubin level in the first case is $1.5 \mathrm{md} / \mathrm{dl}( \pm 2.6)$ and does not differ significantly from the value of bilirubin of naturally born children $1.9 \mathrm{mg} / \mathrm{dl}( \pm 2.9)$. The saturation between 2 and 12 hours in both cases is $98 \%( \pm 1)$, and the heart rate in neonates from caesarean section 122 / min $( \pm 9)$ and natural births $123 / \mathrm{min}( \pm 8)$.

The average age of mothers was 30 years of age $( \pm 5.1)$. There were no significant differences between the influence of age on the type of delivery, in the group of newborns born by force the average age was 30.0 years of age ( \pm 5.8 ), and newborns born via cesarean section 29.4 years of age $( \pm 5.6)$.

Table 3 presents the characteristics of newborns taking into account the age of the maternal mothers. The average age of mothers in the first group is 34 years of age $( \pm 4)$ and is significantly higher than those in the second group, where it main-

\begin{tabular}{|c|c|c|}
\hline & $>30$ years of age & $<30$ years of age \\
\hline $\begin{array}{l}\text { Number of } \\
\text { pregnancies }\end{array}$ & $3 \pm 1$ & $2 \pm 1$ \\
\hline Mother's age [y] & $34 \pm 4$ & $26 \pm 3$ \\
\hline $\begin{array}{l}\text { Pregnancy } \\
\text { termination [week] }\end{array}$ & $39 \pm 1$ & $40 \pm 1$ \\
\hline Apgar scale [pts] & $10 \pm 0$ & $10 \pm 1$ \\
\hline $\begin{array}{l}\text { Weight of } \\
\text { newborns [g] }\end{array}$ & $3489 \pm 550$ & $3773 \pm 458$ \\
\hline $\begin{array}{l}\text { Umbilical cord } \\
\text { blood pH }\end{array}$ & $7,35 \pm 0,06$ & $7,37 \pm 0,04$ \\
\hline Glucose [mg\%] & $72 \pm 12$ & $77 \pm 20$ \\
\hline Bilirubin [mg/dl] & $1,50 \pm 2,61$ & $1,65 \pm 3,02$ \\
\hline Saturation [\%] & $98 \pm 1$ & $98 \pm 1$ \\
\hline Heart rate [bpm] & $124 \pm 12$ & $123 \pm 9$ \\
\hline
\end{tabular}


tains the value of 26 years of age $( \pm 3)$. In the age group above 30 years of age, pregnancy was usually resolved at 39 weeks of pregnancy $( \pm 1)$, and in patients below 30 years of age at 40 weeks of pregnancy $( \pm 1)$. In the case of the older group, the Apgar score was 10 points. $( \pm 0)$ which did not differ from the newborns of the second group - also 10 points $( \pm 1)$. Significant differences can be seen in the weight of children. In the case of children of older mothers it is smaller and amounts to $3489 \mathrm{~g}( \pm 550)$, the average group maintains an average of $3773 \mathrm{~g}$ ( \pm 458$)$. The umbilical cord blood in the first case is $7.35( \pm 0.06)$ without making any significant difference in the $\mathrm{pH}$ of the second group of newborns 7.37 ( \pm 0.04$)$. A small difference in the cord blood glucose level after the age of 30 is $72 \mathrm{mg} \%$ ( \pm 12 ), while in younger patients the mean value is $77 \mathrm{mg} \%( \pm 20)$. Bilirubin in the first case is $1.50 \mathrm{mg} / \mathrm{dL}( \pm 2.61)$ and in the second case $1.65 \mathrm{mg} / \mathrm{dL}$ ( \pm 3.02). In both cases, post-natal saturation is $98 \%( \pm 1)$, and the pulse without significant differences in newborns of older mothers is $124 /$ min $( \pm 12)$, and in younger newborns $123 / \mathrm{min}$ $( \pm 9)$.

Table 4 presents the characteristics of the examined group divided into the weight of the newborns. Newborns below $3500 \mathrm{~g}$ have been born by women pregnant for the third time on average $( \pm 1)$, and newborns over $3500 \mathrm{~g}$ from second pregnancy $( \pm 1)$. The mother's age for the first group of newborns was on average 35 years of age $( \pm 4)$ and was

\begin{tabular}{|c|c|c|}
\hline & $<3500 \mathrm{~g}$ & $>3500 \mathrm{~g}$ \\
\hline $\begin{array}{l}\text { Number of } \\
\text { pregnancies }\end{array}$ & $3 \pm 1$ & $2 \pm 1$ \\
\hline Mother's age [y] & $35 \pm 4$ & $32 \pm 5$ \\
\hline $\begin{array}{l}\text { Pregnancy } \\
\text { termination [week] }\end{array}$ & $39 \pm 1$ & $39 \pm 1$ \\
\hline Apgar scale [pts] & $10 \pm 0$ & $10 \pm 1$ \\
\hline $\begin{array}{l}\text { Weight of } \\
\text { newborns [g] }\end{array}$ & $3059 \pm 386$ & $3861 \pm 369$ \\
\hline $\begin{array}{l}\text { Umbilical cord } \\
\text { blood pH }\end{array}$ & $7,35 \pm 0,05$ & $7,36 \pm 0,06$ \\
\hline Glucose [mg\%] & $73 \pm 14$ & $74 \pm 15$ \\
\hline Bilirubin [mg/dl] & $1,39 \pm 2,31$ & $1,45 \pm 2,44$ \\
\hline Saturation [\%] & $98 \pm 1$ & $98 \pm 1$ \\
\hline Heart rate [bpm] & $124 \pm 10$ & $125 \pm 11$ \\
\hline
\end{tabular}

slightly higher than the mothers of the heavier group of newborns, where it was 32 years of age $( \pm 5)$.

Transient states are observed in the majority of newborns. In the case of newborns born naturally, $44 \%$ of them showed the appearance of various transitional states. When it comes to children born with caesarean section, this percentage was slightly higher and amounted to $56 \%$ of the whole group born this way.

\section{DISCUSSION}

The comparison of neonatal status born via caesarean section and vaginal delivery seems to be a very interesting research problem due to the growing trend among mothers of the future, which is an operating birth, considered as the least risky. Showing the differences between newborns from particular types of delivery is the goal of the above work.

There are many articles about the perinatal state of the newborn. One of them is a paper by Piec et al. [5] in which the postnatal clinical condition of newborns born by caesarean section and vaginal delivery was compared. 485 newborns born by caesarean section and 485 newborns who were born vaginally were randomly selected for the study. In the group of newborns analyzed, it was demonstrated that caesarean section compared with vaginal delivery was associated with more frequent childbirth in the severe condition and more frequent occurrence of acidosis ( $\mathrm{pH}<7.20$ ).

\begin{tabular}{|c|c|c|c|c|c|}
\hline \multicolumn{3}{|c|}{\begin{tabular}{l} 
Table 5 . Simple linear regression an \\
between Week of pregnancy termi \\
Apgar scale \\
\begin{tabular}{c|c} 
Week of pregnancy \\
termination
\end{tabular} \\
\cline { 2 - 3 }
\end{tabular}} & \multicolumn{3}{|c|}{ Apgar scale } \\
\hline & $\mathrm{R}$ & $P$ & $\mathrm{R}$ & & $\mathrm{P}$ \\
\hline $\begin{array}{l}\text { Weight of } \\
\text { newborns }\end{array}$ & 0.659 & $<0.001$ & 0.531 & $<$ & 0.001 \\
\hline $\mathrm{pH}$ & 0.985 & $<0.001$ & 0.919 & $<$ & 0.001 \\
\hline Saturation & 0.981 & $<0.001$ & 0.923 & $<$ & 0.001 \\
\hline Apgar scale & 0.905 & $<0.001$ & - & & - \\
\hline Heart rate & 0.859 & $<0.001$ & 0.802 & $<$ & 0.001 \\
\hline Mother's age & 0.530 & $<0.001$ & 0.590 & $<$ & 0.001 \\
\hline Bilirubin & -0.079 & 0.590 & -0.031 & & 0.831 \\
\hline Glucose & 0.454 & 0.001 & 0.402 & & 0.005 \\
\hline $\begin{array}{l}\text { Pregnancy } \\
\text { termination }\end{array}$ & - & - & 0.905 & $<$ & 0.001 \\
\hline
\end{tabular}


In our own results, it was demonstrated that delivery ended with caesarean section was associated with a slightly reduced Apgar score. There were no statistically significant differences in the umbilical cord $\mathrm{pH}$ values.

The work by Królak-Olejnik et al. [6] compares the post-natal clinical state and the values of anthropometric parameters of newborns delivered by caesarean section. A group of 1648 newborns born in the Department of Perinatology and Gynecology in Zabrze, $66.9 \%$ of all births, was included in the study. The research showed that body weight, chest length and circumference were lower in neonates born via caesarean section.

In their own research, newborns from cesarean section also presented a greater percentage of all births, which was 57\%. A significant difference is the weight of newborns from cesarean section, whose average value in the analyzed material was $3151 \mathrm{~g}$. Our own studies showed a significant relationship between weight and type of delivery, where the average weight of newborns delivered via caesarean section was $3729 \mathrm{~g}$ which was much higher than the birth weight of children with natural births. In many cases the child's weight was an indication for an operative solution to pregnancy.

Study in the neonatal ward requires intensive observation of the newborn immediately after birth, as well as during further days of hospitalization. One of the most important things that have been demonstrated are, first of all, the transient states occurring during the three-day stay in the ward, appearing to a greater extent in newborns born surgically. It has been shown that $61 \%$ of neonates from cesarean section are accompanied by vomiting with fetal water, which is mainly caused by limited contact with the mother. This is indeed a very common condition that is not arguable.

The weight of the child, which affects the type of delivery, can also be considered good and consistent with the actual state of the test. Naturally born newborns have been shown to have lower body weights than those born via caesarean section. Increased weight has been shown in the case of newborns, as well as in children of mothers below 30 years of age.

In the analyzed group of newborns the type of delivery did not have a significant impact on the $\mathrm{pH}$ of the umbilical vein. There were also no significant differences in Apgar scores. The influence of the delivery type on the perinatal state of the newborn has not been proven. Autopsy shows that this result does not refer to the real state.

Childbirth by caesarean section has become a very popular pregnancy solution. Considered among the public as a safe, painless way, with low probability of complications. In fact, it is a method that in many cases saves lives, but sometimes the caesarean section is performed without specific medical indications, often at the request of the pregnant woman, not aware of the negative impact of this birth path on the newborn's condition, which often has huge problems with adapting to ectopic life. Newborns born surgically seem to be more restless and screaming, more likely to vomit with amniotic fluid, to keep their body temperature at a higher temperature, and more often to experience transient and respiratory disorders. Each future parent should be aware that natural childbirth by vaginal route is the best way to terminate a pregnancy if there are no contraindications to it, i.e. a risk to the health or life of the mother and child.

In conclusion, our data indicate that: (1) The average weight of neonates born via caesarean section is higher than the postnatal weight of newborns from vaginal delivery; (2) There is a relationship between the mother's age and the $\mathrm{pH}$ value of umbilical cord blood and postnatal weight of the child; (3) Transient and vomiting are more common in neonates born by caesarean section in the adaptive period; (4) The type of delivery does not affect the $\mathrm{pH}$ of umbilical cord blood of a newborn.

\section{REFERENCES}

1. Chazan B. Successful delivery. PZWL. 2014.

2. Gallagher-Mundy C. Caesarean section. Return to form. Mamania. 2013.

3. Baston $\mathrm{H}$, Hall J. Childbirth. Basics of obstetrics. 2011.

4. Bokiniec R, Gajewska E, Kawalec W. Basics of neonatology. PZWL. 2015.

5. Piec $P$, Suchocki $S$, Obst $M$, et al. Cesarean section and vaginal delivery- impact on neonatal outcome. Perinatologia, Neonatologia i Ginekologia. 2008; 1: 94-97.

6. Baston H, Hall J. Basics of obstetrics. Wroclaw 2011. 